Article

\title{
From Historical Silk Fabrics to Their Interactive Virtual Representation and 3D Printing
}

\author{
Manolo Pérez ${ }^{1}$, Pablo Casanova-Salas ${ }^{1}$, Pawel Twardo ${ }^{2}$, Piotr Twardo ${ }^{2}$, Arabella León ${ }^{3}$, \\ Dunja Mladenic ${ }^{4}$, Besher M. Massri ${ }^{4}{ }^{1}$, Raphaël Troncy ${ }^{5}{ }^{\oplus}$, Thibault Ehrhart ${ }^{5}$,

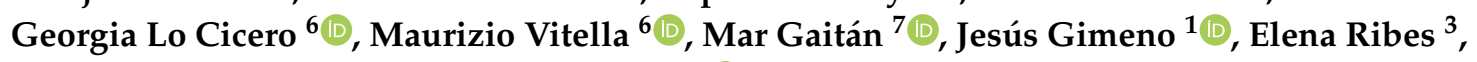 \\ Marcos Fernández ${ }^{1}$ and Cristina Portalés ${ }^{1, *(D)}$ \\ 1 Institute of Robotics and Information and Communication Technologies (IRTIC), Universitat de València, \\ 46980 Paterna, Spain; manolo.perez@uv.es (M.P.); pablo.casanova@uv.es (P.C.-S.); jesus.gimeno@uv.es (J.G.); \\ marcos.fernandez@uv.es (M.F.) \\ 2 MonkeyFab, 04-896 Warsaw, Poland; pawel.twardo@monkeyfab.com (P.T.); \\ piotr.twardo@monkeyfab.com (P.T.) \\ 3 Garín 1820 S.A., 46113 Valencia, Spain; aleon@garin1820.com (A.L.); garin@garin1820.com (E.R.) \\ 4 Jožef Stefan Institute, 1000 Ljubljana, Slovenia; dunja.mladenic@ijs.si (D.M.); besher.massri@ijs.si (B.M.M.) \\ 5 EURECOM, Campus SophiaTech, 06904 Antipolis, France; raphael.troncy@eurecom.fr (R.T.); \\ thibault.ehrhart@eurecom.fr (T.E.) \\ 6 Department of Culture e Società, Università degli Studi di Palermo, 90133 Palermo, Italy; \\ georgia.locicero@unipa.it (G.L.C.); maurizio.vitella@unipa.it (M.V.) \\ 7 Department of Art History, Universitat de València, 46010 Valencia, Spain; m.gaisal@uv.es \\ * Correspondence: cristina.portales@uv.es
}

Received: 19 August 2020; Accepted: 9 September 2020; Published: 12 September 2020

check for updates

\begin{abstract}
The documentation, dissemination, and enhancement of Cultural Heritage is of great relevance. To that end, technological tools and interactive solutions (e.g., 3D models) have become increasingly popular. Historical silk fabrics are nearly flat objects, very fragile and with complex internal geometries, related to different weaving techniques and types of yarns. These characteristics make it difficult to properly document them, at the yarn level, with current technologies. In this paper, we bring a new methodology to virtually represent such heritage and produce 3D printouts, also making it highly interactive through the tool Virtual Loom. Our work involves sustainability from different perspectives: (1) The traditional production of silk fabrics respects the environment; (2) Virtual Loom allows the studying of silk heritage while avoiding their degradation; (3) Virtual Loom allows creative industries to save money and materials; (4) current research on bioplastics for 3D printing contributes to environmental sustainability; (5) edutainment and gaming can also benefit from Virtual Loom, avoiding the need to acquire the original objects and enhancing creativity. The presented work has been carried out within the scope of the SILKNOW project to show some results and discuss the sustainability issues, from the production of traditional silk fabrics, to their dissemination by means of Virtual Loom and 3D printed shapes.
\end{abstract}

Keywords: silk fabrics; weaving techniques; virtual modelling; 3D printing; cultural heritage

\section{Introduction}

The documentation, dissemination, and enhancement of tangible and intangible Cultural Heritage $(\mathrm{CH})$ is of great relevance, as $\mathrm{CH}$ is a fundamental expression of the richness and diversity of our culture. Beyond the well-established methods that have been traditionally employed in the field of $\mathrm{CH}$ for its dissemination and enhancement, technological tools and interactive solutions (e.g., 3D models) have become increasingly popular, because they have the ability to create fascination far beyond 
other solutions, such as a tourist brochure or any other printed material [1-4]. On the other hand, the documentation of artifacts can be done by different means. For instance, the visual appearance is usually acquired with imaging devices; the shape can be documented with stereo-photogrammetry, laser scanning, or structured light-based techniques [5-8].

Silk fabrics have specific characteristics, as they are nearly flat objects and very fragile. Therefore, the documentation of their visual appearance has been traditionally done by means of imaging devices (e.g., RGB cameras, digital microscopes, etc.) [9-11]. However, within these devices, only the surface of the objects is documented, so the complex internal structure composed of a variety of yarns and their interlaces, remains undiscovered. Even if using digital microscopes, the internal structure cannot be properly acquired. Other solutions, such as X-ray or hyperspectral imaging can be used, but requires expensive devices and/or sophisticated techniques to derive the geometry of the internal structure of fabrics [12], hindering their massive use. Additionally, silk fiber is very fragile [13], for instance, and it is considered to have the lowest resistance of all fibers to degradation from ultraviolet light [14], so its use to document such objects can damage the fabrics.

To deal with a more complete and massive documentation of such heritage by taking into account the internal geometry of the fabrics and avoiding their degradation, we bring a new methodology in the scope of the SILKNOW project. Our solution brings 3D models of silk fabrics at the yarn level, with the minimum information of an image taken with a conventional camera. Additionally, we have developed online interactive tools, which are also open source, that allow the dissemination and enhancement of this valuable legacy.

SILKNOW is an EU funded research project that improves the understanding, conservation, and dissemination of European silk heritage from the 15th to the 19th century. It applies advanced computing research to the needs of diverse users (museums, education, tourism, creative industries, media, etc.), and preserves the tangible and intangible heritage associated with silk [15]. Among others, we have developed "Virtual Loom" (VL), an application that deals with the 3D virtual representation of historical silk fabrics at the yarn level [16-18]. We have also investigated how to materialize the generated 3D models by means of 3D printing technology. For the implementation of such a tool, a deep study of the way historical silk fabrics were produced (techniques, yarns, etc.) was needed. Therefore, the definition and computational modelling of historical weaving techniques has been possible thanks to a tight collaboration among experts in computer engineering and domain experts related to the production of silk textiles.

In this paper, we present a review of traditional silk textiles as tackled in the SILKNOW project, from their traditional production, to their 3D representation both virtually (with Virtual Loom) and as printouts, specially focusing on the designs, weaves, and weaving techniques. Although preliminary versions of Virtual Loom have been previously reported [16-18], we focus here on the advancements (e.g., improved 3D graphics and integration in ADASilk) and the production of 3D printouts to represent designs and weaving techniques. We also show some results from the project, and discuss their use within different audiences, including the creative industries. The work described involves sustainability from different perspectives: (1) The traditional production of silk fabrics by means of mechanical looms (e.g., Jacquard looms) is sustainable from the point of view of the environment because it does not use energy when working; (2) the embedding of designs, weaves, and weaving techniques in 3D virtual forms allows the study of this historical legacy without the need to have direct access to the original objects, which are per se fragile, and therefore, avoiding their degradation; (3) embedding the same designs in Virtual Loom allows creative industries to save money and materials as they can show finished designs on fabrics to their clients without having to weave them; (4) current research on bioplastics for 3D printing is promising, greatly contributing to environmental sustainability; (5) edutainment as a creative industry itself, can benefit from this type of application as they can be transformed into videogames [19]. They can also be used in classrooms where Information and Communication Technologies (ICT) can be mixed with other games and creativity, as weaving 
implies to not only be aware of our own heritage but also to be able to understand space, design, and color, and also mathematical concepts such as iteration or symmetry [20,21].

The paper is distributed as follows. In Section 2, the state of the art is reviewed and the novelties we bring are discussed. In Section 3, we explain the methodology used in SILKNOW for the virtual representation and $3 \mathrm{D}$ printing of silk fabrics, also showing some results for a given example. In Section 4, we discuss the sustainability aspects related to our tools to document historical silk fabrics. Finally, some conclusions are given.

\section{State of the Art}

\subsection{The Production of Traditional Silk Textiles}

The first evidence of fabric made with natural fibers dates back to prehistoric times. Humankind had the need to protect their body from temperature fluctuations and external agents. The realization of the fabrics, born from the desire to respond to a primary need for protection, later absorbed social and anthropological connotations. In fact, the fabrics, and their sartorial use to create clothing, have become a means to express the personality of people, declare the membership of belonging to social groups, or their status [22]. The most ancient arrangement of fibers, to constitute a weave, was inspired by the fishing net or the one used to make baskets or furnishings, weaving by hand the vegetable fibers that were available [23]. Yet, the real revolution was the creation of the loom, which over the centuries, in its various evolutions, became an irreplaceable companion of family and social life, and above all it has been a booster for the economy, thanks to its mechanization, particularly in the industrial era. The use of a precious fiber, such as silk, had a profound influence on history and human society. Silkworm breeding is a perfect system of a circular economy and has a very low environmental impact thanks to its complex production process involving humans and the environment [24]. To these great artistic results of the fabrics made with silk are added, thanks to the expertise of specialized workers.

Over the centuries, from the simple plain weave, the mother weaving from which all the others evolve, the skills of weavers have come to create increasingly complex fabrics, called textured fabrics, which are precious as true works of art. In the field of silk weaving, the weave is called taffeta. A simple two shafts loom is sufficient to make it. Each warp yarn passes alternately above and below the successive wefts. It forms a compact and uniform fabric with no reverse side. The working of the textured fabric, such as brocade for example, required a lot of attention and experience. For this type of fabric, it is necessary to work different additional weaves, and it requires the intervention of several weavers. In fact, the textured fabrics were made with a loom operated by a weaver and one or two helpers. Standing above the loom, they operated the device for the formation of the shed. All this happened while they were reading the drawing to be made from a point paper plan [25-28].

The working of textured fabrics was made easier thanks to the invention of Joseph-Marie Jacquard [28-31], who created a mechanism adapted to the loom that revolutionized the world of fabric production in the 19th century. It allowed very complex processes carried out by a single weaver. The manufacturing process was simplified by simultaneously producing effects on the fabric. The prototype made by Jacquard was presented in Paris in 1801. He used in a single machine the improvements applied to the loom by Bouchon, Falcon, and Vaucanson.

In fact, the Jacquard machine modified the classic loom. This allowed the simultaneous raising of hundreds of yarns with a single movement by using a system of pedals. A highly skilled workforce was no longer required, and production was increased. The pedals lift the necking cords, the leashes, and the relative warp yarns run into them, according to the established design. All this happens by means of a chain of a tablet weaving with a series of perforated cards, representing the design to be executed. For the textured fabrics requiring more warps, the ground warp has its own series of traditional healds connected to the pedals, allowing the movement of the ground weave (taffeta, twill, or satin), which is alternated with beats of the design. By pushing the pedals, the weaver can alternate 
beats for the ground weave with beats for the design, in which the perforated cards will only raise the yarns of the design, or the pile in the case of velvet [26-28].

As a matter of fact, this made weaving cheaper for producers because it required less labor and allowed a wider spread of textured fabrics. The Jacquard loom, with its perforated weaving system, is considered the forerunner of the modern computer [22]. The fabrics trace the history of humankind and thanks to the perforated cards, handed down over time, it is still possible to replicate ancient and precious fabrics today. In fact, thanks to careful safeguarding operations, some textile manufacturing companies still produce fabrics today using ancient looms suitable for reading perforated tablets, as shown in Figure 1. The recovery of ancient weaves, preserved from oblivion, safeguard an important piece of human history.

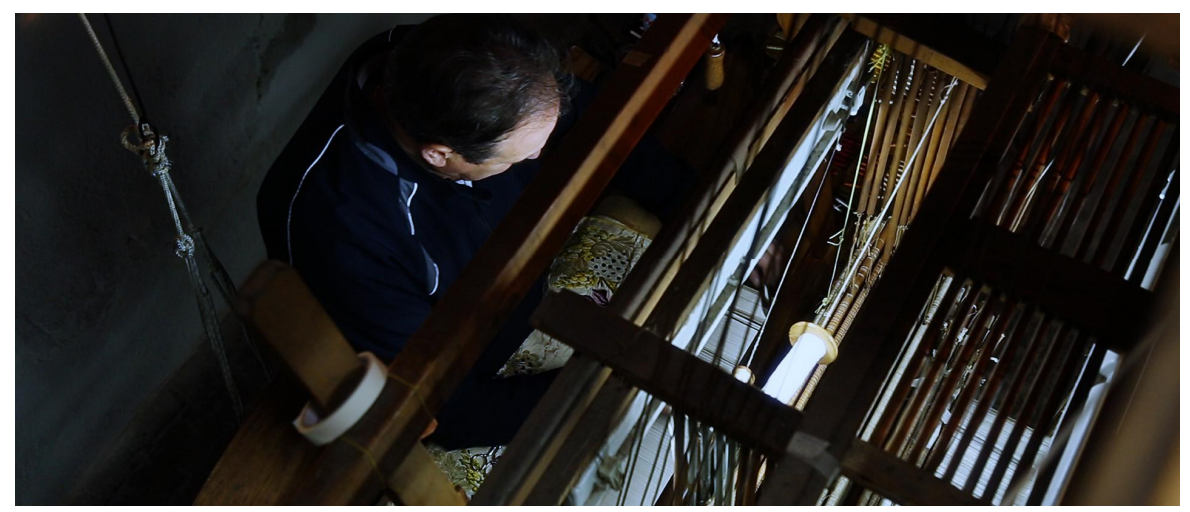

Figure 1. Jacquard looms currently being used to weave traditional textiles at the Garín 1820 factory (Valencia, Spain) [32].

\subsection{Virtual Representation of Fabrics}

The virtual representation of fabrics and clothes in 3D forms is a widely investigated area, where different topics are included. For example, [33] deals with real-time 3D clothes rendering while [34] or [35] investigate how to reproduce the physical movement of knitted clothes. In our study, historical silk fabrics are represented in 3D at yarn level and in real-time, so different aspects must be taken into account: the visual aspect of silk yarns, different weave techniques, performance of the visualization software, etc. It has to be noted that, in our case, the represented fabrics are static, so the physical simulation and its performance are not tackled. To get a better understanding of how historical silk fabrics are weaved, Virtual Loom creates a realistic 3D view at the yarn level. The objective is not to create a full cloth piece, but to provide closer views of the fabrics, where realistic silk yarns are weaved to create patterns and drawings. Other works deal with closer representations of fabrics, such as in [33], that presents a (Graphics Processing Unit) GPU-based technique to render full cloth pieces, at fiber level. In this study every yarn is formed by fibers, so the full cloth involves millions of polygons. The geometry of each fiber is instantiated on the GPU to improve the performance. Moreover, different levels of detail are proposed, so the geometry is simplified and different textures (height-maps, self-occlusion maps, normal maps, etc.) are used to simulate the different fibers of each yarn. In Virtual Loom a similar approach is used, simplifying the yarn's geometry, and implementing a shader to simulate the fibers' geometry. A key difference with previous works, is that in historical silk fabrics, complex yarns are used, e.g., silks with a metallic cover, so a specific shader has been implemented with two main objectives-create a realistic yarn-level zoomed view while keeping a good performance, so most of the users can use this tool.

Virtual Loom allows users to weave historical fabrics, so the definition of the textile structure and properties is a key aspect. In this regard, in [36] it is proposed a general model to describe the structural hierarchy of textiles, which is the basis of WiseTex [37,38]. WiseTex is an integrated modeling and design tool, where different yarns can be created, and also the structure of the textile. All the 
definitions are made using low-level parameters, so the tool requires an important training effort and previous knowledge about textile structures. TexGen [39] allows the creation of textiles, also with different structures and yarn types. In this case, the visual appearance is not realistic because the main objective of the tool is to analyze the physical properties of the textile, e.g., elasticity or strength. In both cases, different matrices are used to define the textile structure; in other words, how yarns go up-down, above, or under other yarns to create the fabric. In Virtual Loom, matrices are also used to define different historical techniques. An important difference is that Virtual Loom is targeted to expert and non-expert users, so we provide an easy-to-use interface, with clear steps to follow. In this case, the user will start with a photograph, which can be virtually weaved using pre-configured historical techniques and silk yarns. Configuration parameters are available, allowing the selection of the area of the photo, deciding about the number of yarns, or changing the color and geometry of yarns.

\subsection{D Printing of Fabrics}

Three-dimensional printing is a technology with a lot of potential uses in $\mathrm{CH}$. For instance, in [40], the use of this technology is emphasized for preservation, accessibility, research, and education in $\mathrm{CH}$, and its use in museums is discussed. Researchers highlight the relevance of having access to a tangible, 3D reproduction of artifacts, for persons with learning difficulties, for children, the elderly, and for blind or visually impaired visitors. In [41], 3D printing technology is combined with virtual reality and augmented reality to bring added value to visitors in $\mathrm{CH}$ places. Additionally, in [42], a survey is presented, with multiple examples of 3D printed sculptures making use of a variety of techniques. However, this technology needs more research in $\mathrm{CH}$. For instance, in [40], the necessity to develop basic guidelines for 3D printed models is addressed. In SILKNOW, we bring guidelines to print historical fabrics, both focusing on the design and on the weaving techniques (Section 3.3).

Regarding the state of the art of 3D printing related to fabrics, two techniques exist nowadays: (1) 3D printing on fabrics (e.g., [43]), which consists of printing and attaching 3D shapes on existing fabrics (e.g., Lycra); (2) 3D printed shapes (e.g., [44]), which consists of printing individual 3D shapes, and sometimes joining them to form clothes. However, research studies are still incipient and none of the techniques are mature enough to allow the massive fabrication of textiles with 3D printers [43-46]. For instance, one of the major problems for printing on the fabrics is how to attach the fabric to the machine's platform. Usually, double sided adhesive tape is used, but it is not the best solution at all, as it leaves the glue on the fabric, and it is not comfortable for long-term work. Additionally, for printing on fabrics, it is very important to set the distance between the fabric and the nozzle. It is crucial to almost press the nozzle into fabric, for better adhesion, but also it must be a careful process to avoid damaging the fabric. This is a problem not yet solved by current $3 \mathrm{D}$ printing technologies. On the other hand, regarding 3D printed clothes, one major problem is how to detach the 3D printed chainmail from the surface of the platform in a quick and simple manner. Today, a glass or alloy platform is mostly used, and it works perfectly with medium size and big 3D printed objects. However, when it comes to a mass of little cells, it is very easy to destroy or damage the model during detachment (especially, when the object contains hundreds of cells, like a dress). Additionally, for both 3D printing technologies, large-scale 3D printers (for example, $1 \times 1 \times 1 \mathrm{~m}$ ) are not space efficient machines.

In the scope of the SILKNOW project, we are tackling these issues in order to step forward in the textile 3D printing technology, both printing on clothes and printing clothes or pieces. To that end, the company MonkeyFab is investigating in the adaptation of their own Fused Filament Fabrication (FFF) 3D printers for these purposes, and a collaboration with a fashion artist is being developed for printing on fabrics and printing pieces that will be joined forming clothes. There is a variety of examples of fashion artists and designers experimenting with 3D printing, such as Janne Kyttanen [47], Iris Van Herpen [48], and Noa Raviv [49]. However, in the scope of this paper, we will focus only on the methodology and guidelines to reproduce historical fabrics, by printing pieces that represent certain designs and weaving techniques (Section 3.3). It is also relevant to highlight, that most works related to $\mathrm{CH}$ which make use of $3 \mathrm{D}$ printing, are intended to reproduce volumetric figures (e.g., statues, 
buildings, etc.). To the best of our knowledge, 3D printing of historical fabrics is one of the novelties of our work.

\section{Methodology and Results}

Figure 2 brings an overview of the methodology developed in SILKNOW for the virtual representation and 3D printing of silk fabrics, where the input parameters for Virtual Loom are an image and related information (e.g., weaving technique) that describe a given fabric.

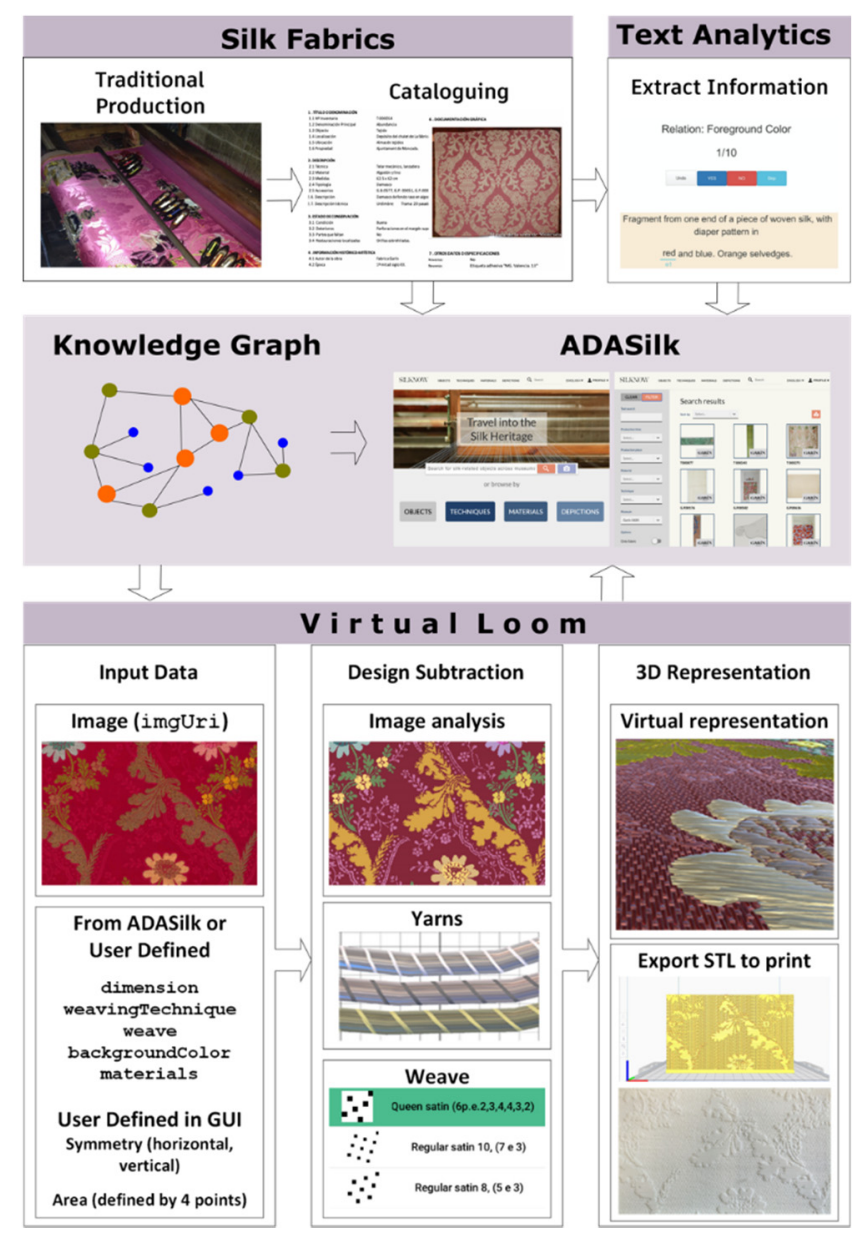

Figure 2. Overview of the methodology developed in SILKNOW for the virtual representation and 3D printing of silk fabrics.

Virtual Loom is an open source software module, fully designed and implemented in the scope of the SILKNOW project, that embeds historical weaving techniques in order to produce 3D models of textiles, given an input image with related information. It also allows the exporting of the generated models in STL (stereolithography) format, in order to produce 3D printouts. The first release version was described in [16,18] and a work focusing on symmetry is also available at [17]. Therefore, in this section we will focus on addressing the novelties regarding the first version and on showing some results for different weaving techniques. The reader is referred to our previous works for more information. The code can be accessed through the SILKNOW's GitHub repository [50], online releases are also available at [51], and a video tutorial can be accessed at [52].

Currently, Virtual Loom is being integrated as part of ADASilk (Advanced Data Analysis for Silk heritage) [53], an exploratory search engine built on top of the SILKNOW's knowledge graph that contains nearly 40,000 fabric entries with images and other relevant information describing them (e.g., production place, production timespan, material, technique, etc.). This information is 
enriched by text analytics, that automatically extracts data from the textual description of silk fabrics (see Section 3.1).

Concretely, metadata about fabrics together with illustrating images are collected from various museums and represented using a common model, the CIDOC-CRM (Conceptual Reference Model) ontology. This creates a knowledge graph encoded in RDF that is being made available to third party applications using a dedicated API [54]. ADASilk follows this structure. It belongs to the family of exploratory search engines which is a particular information seeking activity, open ended, generally evolving, with multiple targets and goals, multifaceted and characterized by a serendipitous attitude [55]. The primary goal of the exploratory search engine is to enable users to search for silk fabrics using complex queries while also discovering collections of objects that are today scattered across numerous museum web sites. Clicking on individual objects enables to see the full set of metadata that has been collected for this museum object.

Virtual Loom is a Unity technology development build available for three different environments: Windows (native), MacOS (native), and WebGL (to run within the context of a web browser). The integration with ADASilk has been done using the WebGL version. The Virtual Loom WebGL component is launched when a user selects the 3D visualization button available from the detailed view of an object described in the SILKNOW knowledge graph. The design embedded in a fabric can be automatically extracted by means of image analysis. To that end, users can tweak some parameters and configurations in order to subtract the background of the image and the pictorial part(s). As part of the design, Virtual Loom offers a variety of yarns, weaves, and weaving techniques which can be applied (with some restrictions depending on the techniques). The generated image, as well as the selected parameters (e.g., yarns, weave), are then used to produce a 3D interactive representation of the fabric, which can also be exported in STL form.

\subsection{Text Analytics to Automatically Extract Data for Virtual Loom}

Text analytics methods can be used for automatic extraction of information from textual descriptions of silk [56], such as background and foreground color, weaving technique, or weaving style. We have developed a text annotation service for domain experts to annotate text excerpts that are then used to train a machine learning model for automatic extraction of information. The initial experiments are taking text data from two of the museums, defining two tasks: a color annotation task and a number annotation task. The two considered museums are VAM (Victoria and Albert Museum) for English texts, and CER.ES (Colecciones en Red) for Spanish. In the first task, we ask the domain experts to annotate selected parts of texts from the museum that contain mention of a color. The possible annotations related to specific colors are: background color, foreground color, border color, or other. In the second task, we ask the domain experts to annotate selected parts of text from the museum that contain mention of a number. The possible annotations related to specific numbers are: number of yarns, dimension, section, rapport, colors, or other.

We have selected these two tasks as relevant for our Virtual Loom, where the dimension, the number of colors, and the background color can be used. Figure 3a shows an example of the color annotation interface, where the user is asked to annotate "blue", which is underlined in the text.

Based on the initially annotated texts, we have formed two active learning models, one for each task, focusing on the most frequent label from the task-foreground color and the number of sections. The domain experts were then asked to annotate text excerpts for these two labels, answering yes/no. See Figure 3b for illustration of the annotation interface, where the user is asked to annotate "red" that is underlined as referring to foreground color or not. In case the answer is not clear to the user, they can "Skip" the example and proceed to the next one.

We have represented texts with commonly used (Term Frequency Inverse Document Frequency) TFIDF word-vector representation and used a Support Vector Machine algorithm to train the models on English and Spanish texts. For English texts, the foreground color model was trained on 100 examples and tested on 200 examples. The model has achieved 65.5\% classification accuracy and 78.4 F1 
measure. For the number of sections, we have trained a model on 63 examples and tested on 139 examples, while the model for the number of sections has achieved $57.6 \%$ classification accuracy and 57.6 F1 measure. For Spanish texts, the model was trained on almost 100 examples and tested on about 100 examples, achieving 75\% classification accuracy and $47.0 \mathrm{~F} 1$ measure for the foreground color and 79\% classification accuracy and $52.0 \mathrm{~F} 1$ measure for the number of sections.

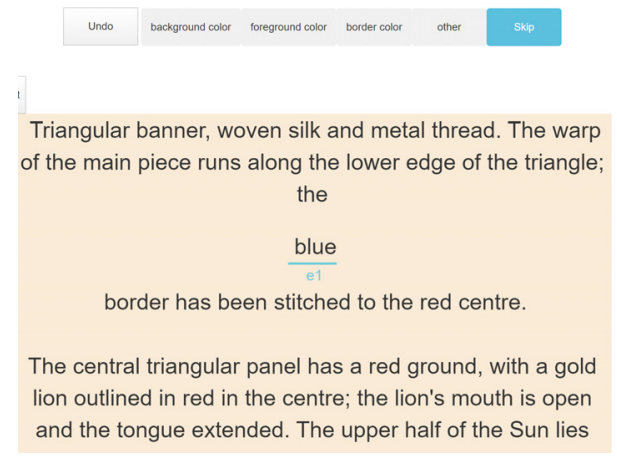

(a)

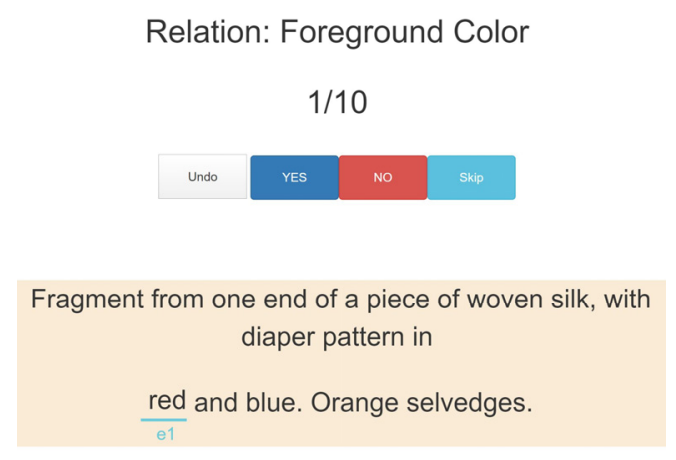

(b)

Figure 3. Example screenshot of the annotation interface: (a) annotation interface for Victoria and Albert Museum (VAM) color annotation task; (b) annotation interface for foreground color annotation where an active learning model is selecting which texts to show to the user for annotation.

The annotation tasks were selected as the mentioned labels were found relevant for the domain and it is usual to find these descriptions in the catalogue records. This is basic data both for the fabrics and weaving techniques. In this regard, the information selected is in relation with Virtual Loom, as it represents the ways in which a textile can be weaved, providing information such as the number of yarns, its density, colors, etc. Rapport, for example, represents the basic unit that is composed of one or more motifs, which, by repetition, constitute a pattern of a textile that give the conservator the design dimensions, hence the textile dimension, and can even be used for dating purposes. Even though it is an important and necessary piece of information, not every museum specifies a field for rapport in metadata, so that on most occasions it appears within the text.

\subsection{Interactive Virtual Representation of Silk Fabrics}

There are five historical techniques implemented in Virtual Loom, which are damask/damassé, damassé with metallic weft, lampas, espolín, and espolín with damassé ground. We have also integrated ten types of yarns (3 variations of silk, 3 types of silk with gold, 3 types of silk with silver, and cotton) and a total of 39 weaves (tabby, twill, satin, and variations). Additionally, to expand the use of Virtual Loom to big audiences and the creative industries, we have implemented a weaving technique called "freestyle", from where all types of weaves and modelled yarns can be used, thus allowing the experimentation with new forms of generating 3D models for a given design.

For all techniques, users can also experiment by changing the color of the yarns, increasing/decreasing the number of yarns, increasing/decreasing the number of zones (of the design), mirroring an image to complete a design, etc. The generated 3D models can be downloaded, as well as the design after the posterization of the image. Additionally, Virtual Loom allows users to upload any image. Therefore, they can upload their own design, in order to virtually weave it and produce a 3D model.

In Figures 4-6, some 3D reproductions of a historical fabric are shown, which have been weaved making use of Virtual Loom v0.96b. The fabric belongs to Garín's collection, and its image is available in ADASilk. In Figure 4a, the image of a historical silk fabric is loaded in Virtual Loom; the four green squares on top of the image limit the area that a user has selected. The image to the right shows the result of applying a perspective correction (by default), a vertical axial symmetry to the 
selected area (selected by user), and an aspect ratio of 1.11 (selected by user). The image to the right in Figure $4 \mathrm{~b}$ shows the result of applying two clusters. Note that the pictorial part of the original image is composed of two colors (white, grey) instead of one, which makes a total of three colors taking into account the ground (blue), but, as the user has indicated two clusters, the pictorial part is merged into a single color. Furthermore, in Figure $4 \mathrm{~b}$, it can be seen that the user has selected the weaving technique damask/damassé. The result of this selection applies to certain restrictions in the next step, which can be seen in Figure 4c. Here, the user has to select the background cluster, which corresponds to the fabric's ground. They can also edit the weave, colors, and types of yarns. In the example, the user has kept the default settings and changed the color of the cluster corresponding to the pictorial part. Finally, in Figure 4d, the 3D model is depicted at the yarn level, together with a general view (top left). The user can rotate, zoom in/out, and pan the model. They can also navigate through the model by moving the square that appears on top of the general view.

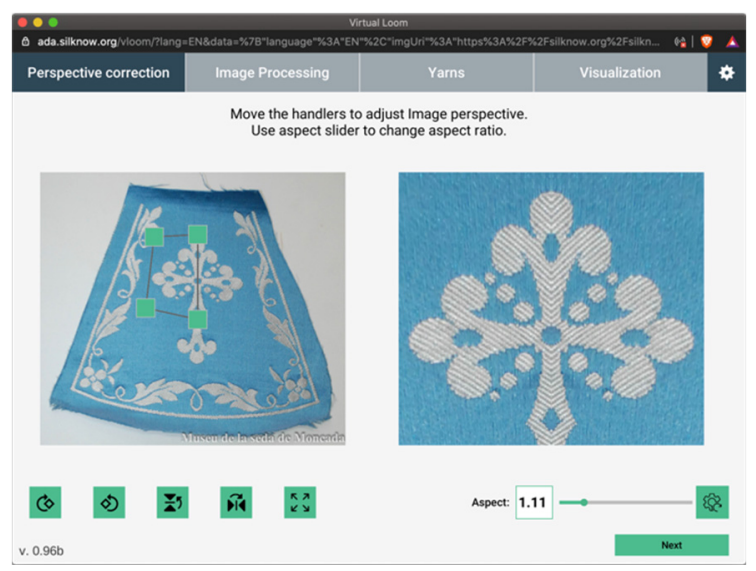

(a)

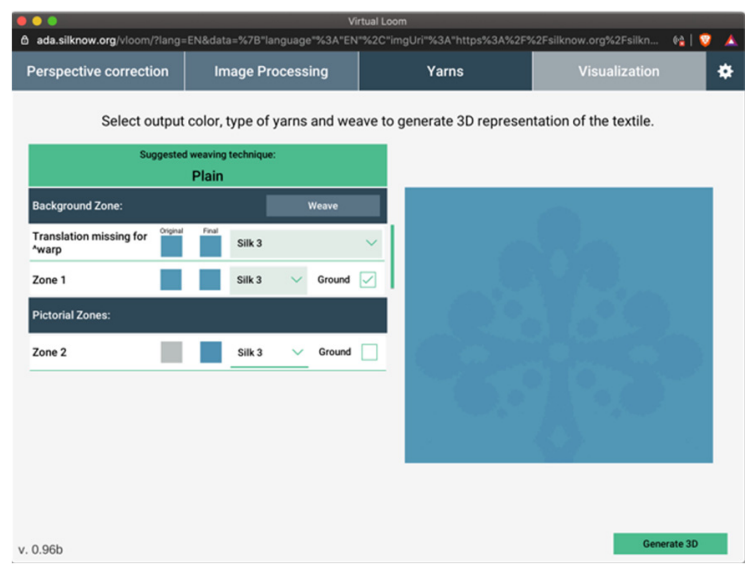

(c)

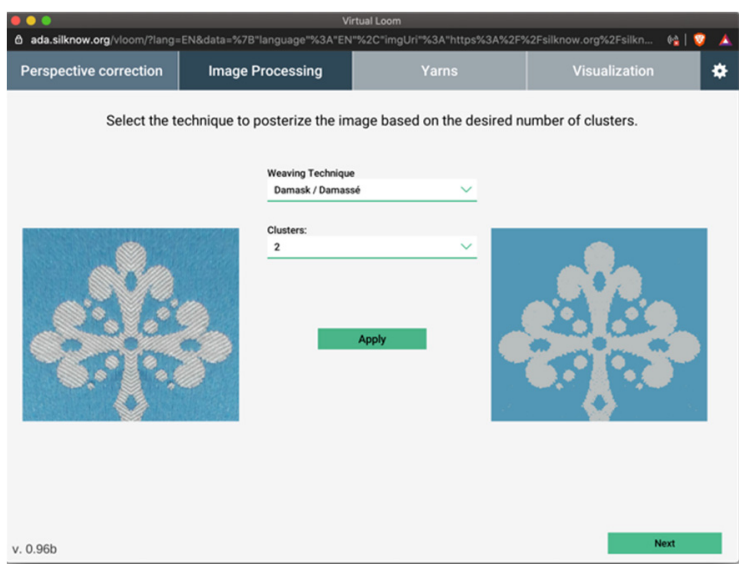

(b)

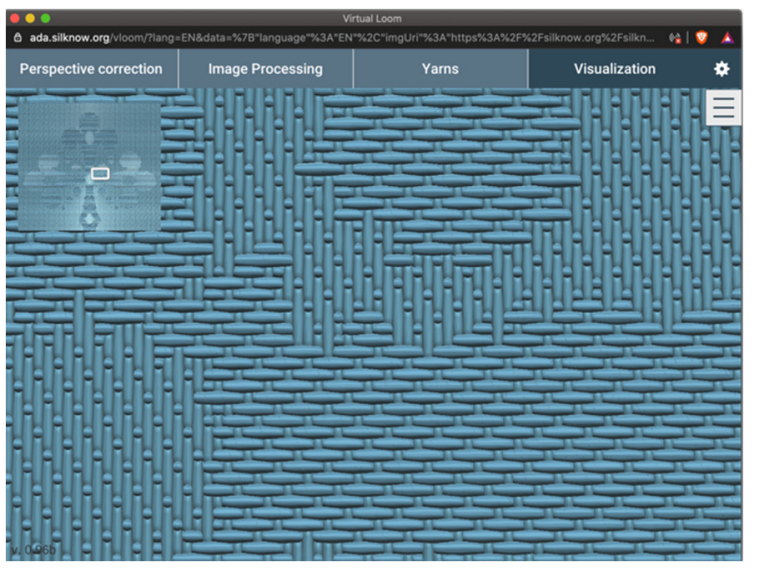

(d)

Figure 4. Example for the 3D reproduction of a historical fabric (from Garín) in Virtual Loom v0.96b (integrated in ADASilk), with the damask technique: (a) original image loaded in Virtual Loom, area selection, application of a vertical axial symmetry and aspect ratio fitting; (b) selection of the technique and number of clusters; (c) background, weave, yarn, and color selection; (d) interactive virtual representation. 


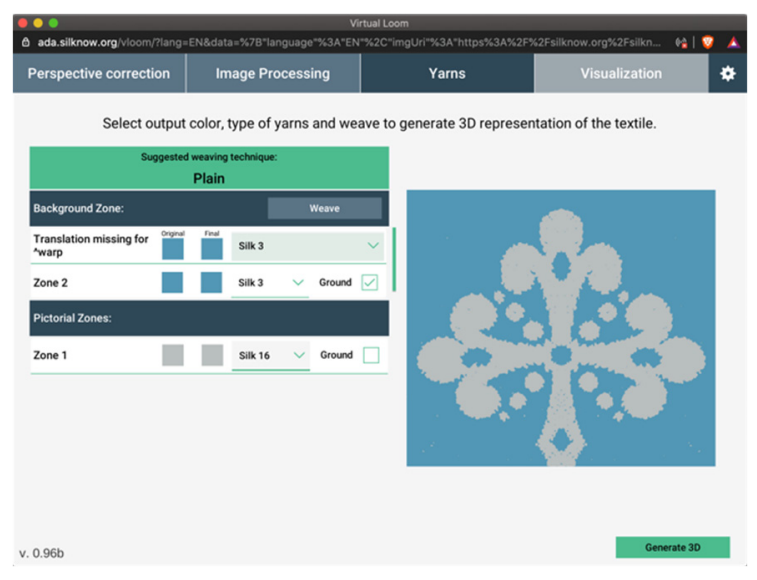

(a)

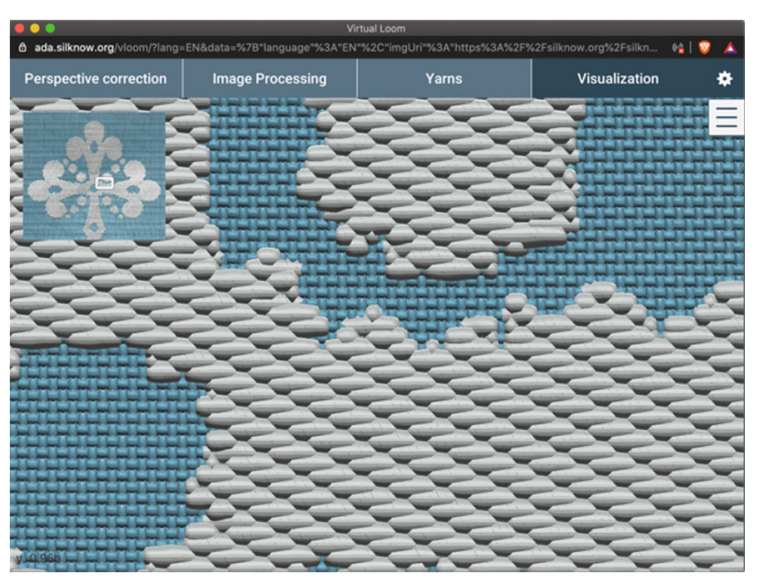

(b)

Figure 5. Example for the 3D reproduction of a historical fabric (from Garín) in Virtual Loom v0.96b (integrated in ADASilk), with the lampas technique: (a) background, weave, yarn, and color selection; (b) interactive virtual representation.

In Figure 5, the lampas technique is used for the same image (and area) as in Figure 4.

In this case, also two clusters and an aspect ratio of 1.11 are applied. In Figure 5a, it is shown that the user has changed the yarn of the pictorial part to Silk-16. Figure $5 b$ shows the generated model for an area similar to the one shown in Figure 4d. As it can be seen, their geometries are different, as they correspond to different weaving techniques and different types of yarns.

In Figure 6 the freestyle is used, for the same images (and areas) as in Figures 4 and 5. In this case, three clusters are applied, and an aspect ratio of 1.11 is used. In Figure 6a, it is shown that the user has changed the colors of both yarns that correspond to the ground (warp and weft), and in the pictorial part has selected a silver yarn for one of the pictorial zones. Figure $6 \mathrm{~b}$ shows the generated model, for an area similar to the one shown in Figures $4 \mathrm{~d}$ and $5 \mathrm{~b}$. In this case, the generated geometry for the ground is similar to that shown in Figure $4 d$, because the same weave (Queen satin, see Figure $6 \mathrm{c}$ ) and types of yarns are applied. Another result is shown in Figure $6 \mathrm{~d}$, where the user has changed the default weave, using an extended tabby instead. The image representing extended tabby is the one highlighted in Figure 6c, which consists of an image of $4 \times 4$ black and white pixels. This will indicate to Virtual Loom how to interlace the weft and the warp yarns. As it can be seen, Figure $6 b, c$ only differ on the ground, as it is there where the weaves apply.

Taking into consideration the number of weaves implemented in Virtual Loom (a total of 39) and the number of yarns with different geometries (only five, as all the considered metallic yarns share the same geometry), for an image with three clusters (that means four yarns, as the ground is made of two yarns), like the one shown in Figure $6 a$, a total of $39 \times 5 \times 4=780$ different models can be achieved. Additionally, the user can choose between weaving the pictorial part as brocaded or not, so this doubles the number of models.

Note that, for historical weaving techniques, less outputs are possible, because not all the weaves or yarns are available. For instance, the ground of a damask is usually made of certain types of satin weaves, and the two yarns forming the ground and the pictorial part (weft and warp) are of the same width (Silk-3) and color (if there is a variation, then it is considered a damassé instead). Such restrictions are taken into account when selecting the weaving technique in Virtual Loom. 


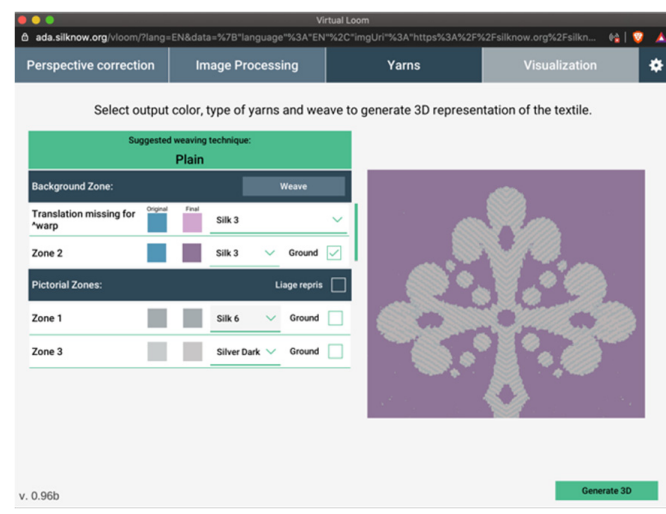

(a)

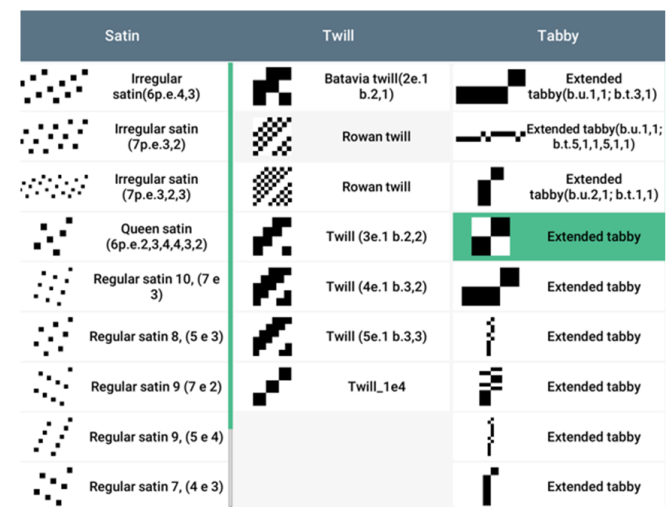

(c)

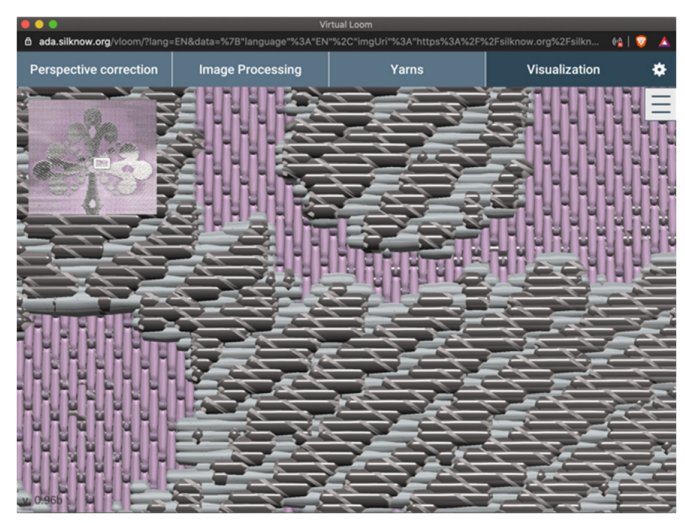

(b)

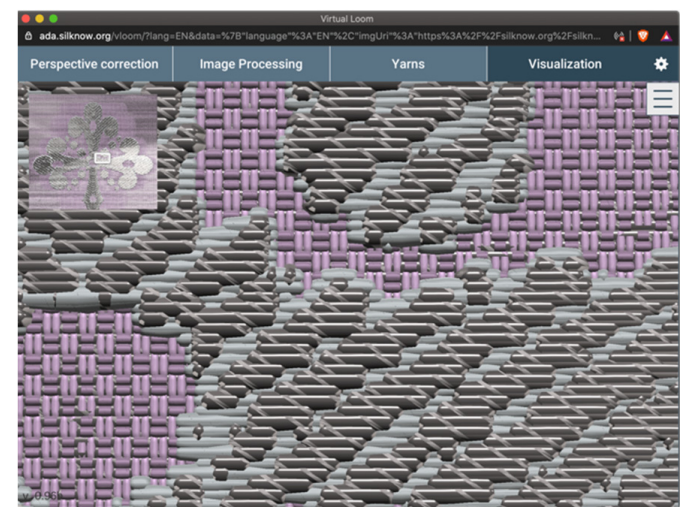

(d)

Figure 6. Example for the 3D reproduction of a historical fabric (from Garín) in Virtual Loom v0.96b (integrated in ADASilk), with the freestyle technique: (a) background, weave, yarn, and color selection; (b) interactive virtual representation; (c) weave selection: extended tabby; (d) interactive virtual representation with extended tabby for the ground.

\subsection{D Printing of Silk Fabrics}

As shown in Section 3.2, the samples from Virtual Loom can be very large and detailed, which is to be expected when dealing with fabrics. The samples display the interwoven yarns with great precision and are extremely valuable for the exploration of different weaving techniques. These same properties make them harder to print on common Fused Filament Fabrication (FFF) 3D printers-which is the most widely used 3D printing technology, and the one we use in the project. To allow them to be printed successfully, and to achieve high quality, 3D processing is needed (explained in the following sub-sections).

The aim of 3D printing a fabric sample can be twofold-to show the pattern on the fabric or to investigate the weaving technique. These two goals require models with different sizes and characteristics that need to be processed in different ways, and both are investigated in SILKNOW.

\subsubsection{Models Used to Show the Design}

Models used to show the design cover a larger area of the sample and details of interwoven yarns are unnecessary. Furthermore, such details often cause problems in the slicing process. A large area of a fabric is also very thin and, as such, impossible to print with the current technologies. Therefore, the samples represented in the VL need to have several modifications. The re-meshing procedure consists of the following steps, as shown in Figure 7: 
1. Project a dense mesh grid onto the model from both sides: To create a watertight uniform mesh out of the sample, the grids are projected onto the sample from both sides. The density (number of rows and columns) in the grid and the resolution of the sample determines the resolution of the output mesh. This projection results in two separate grids, deformed accordingly to the base sample.

2. Move the two projected grids apart from each other to add the width: To add the width to the final mesh, the two grids should be separated from each other by a few $\mathrm{mm}$. This ensures that the model will be thick enough for the slicing algorithm.

3. Close the gaps between the grids: To create a watertight model, the grids must be connected together. This is achieved by bridging the opposite grid edges.

4. Model the stand: Even after adding thickness by moving the grids, these few $\mathrm{mm}$ can be too little to print reliably. Thin models are prone to falling. To ensure the printing process will be successful, an additional stand is added.

5. Imprint the name of the fabric onto the stand (optional): In the scope of the SILKNOW project, there are many samples of historical silk fabrics that involve different designs and techniques. Therefore, having the sample name imprinted on the stand is desirable for learning purposes and to keep the printed samples in order.

6. Join the grids to the stand into a watertight mesh using a Boolean union operation: The final step is to create one unified mesh out of the design mesh and the stand. This is achieved with a Boolean union operation. Boolean operations on triangular meshes are especially tricky for all 3D software, and it is not uncommon to create an erroneous Boolean mesh. It is advisable to check the final mesh for errors before printing. The final mesh is shown in Figure 7e,f.

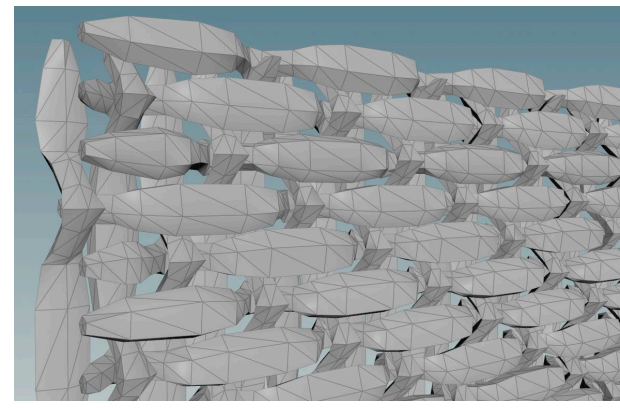

(a)

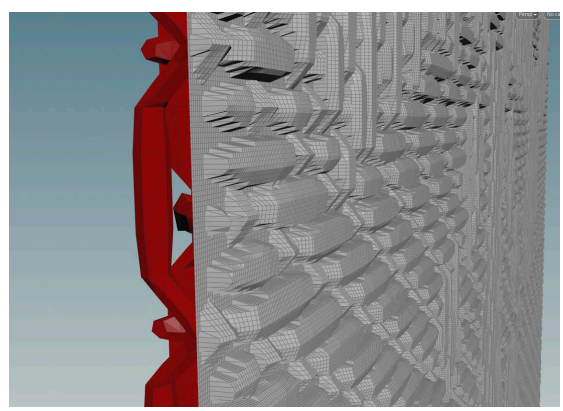

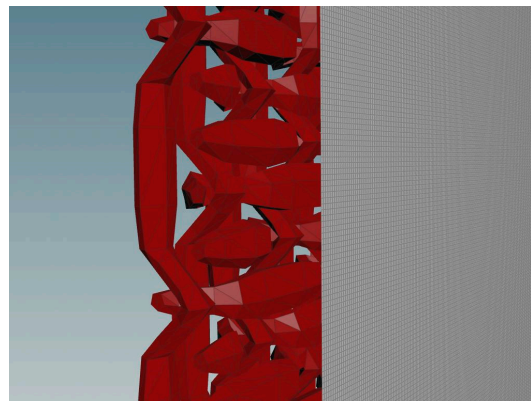

(b)

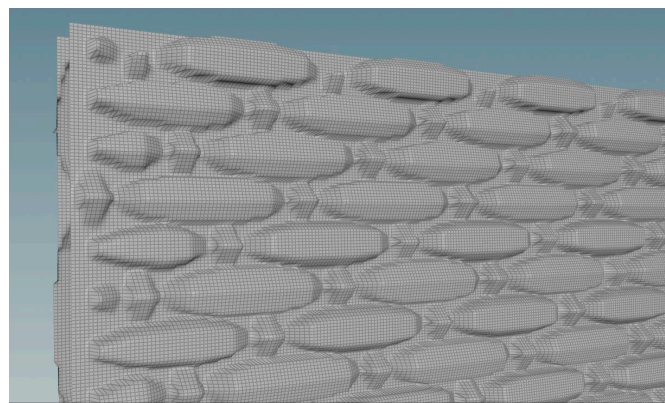

(d)

Figure 7. Cont. 


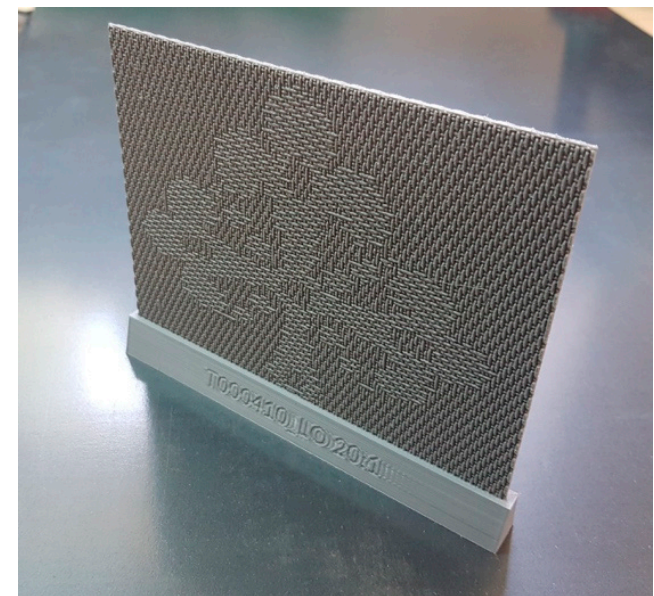

(e)

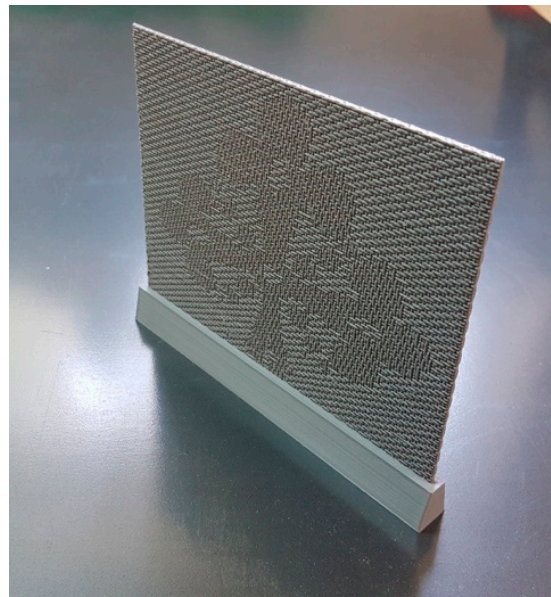

(f)

Figure 7. Models used to show the design of a given fabric: (a) disconnected mesh with gaps; (b) high resolution grid against the model; (c) the grid projected onto the model; (d) watertight front surface of the model; (e) fully remodeled sample, front side; (f) fully remodeled sample, rear side.

\subsubsection{Models Used to Investigate the Weaving Techniques}

The models for the investigation of weaving techniques show only a fragment of the fabric but should be enlarged several times, as shown in Figure 8a. The fragment has to be chosen and cut out of the original model. Such an enlarged model consists of a number of separated yarn meshes arranged horizontally and vertically. The horizontal yarns would force the slicing algorithms to create additional support structures which would contaminate the final result. To avoid this, the model has to be rotated 45 degrees before cutting out a fragment. Then, all of the yarns are oriented diagonally to the printing platform and are thus safe to print. After cutting, the resulting hole in the mesh is closed, as shown in Figure $8 \mathrm{~b}$. Therefore, the re-meshing procedure consists of the following steps: (1) enlarge the model; (2) rotate 45 degrees; (3) cut out the desired fragment; (4) close the holes; (5) add a stand (optional).

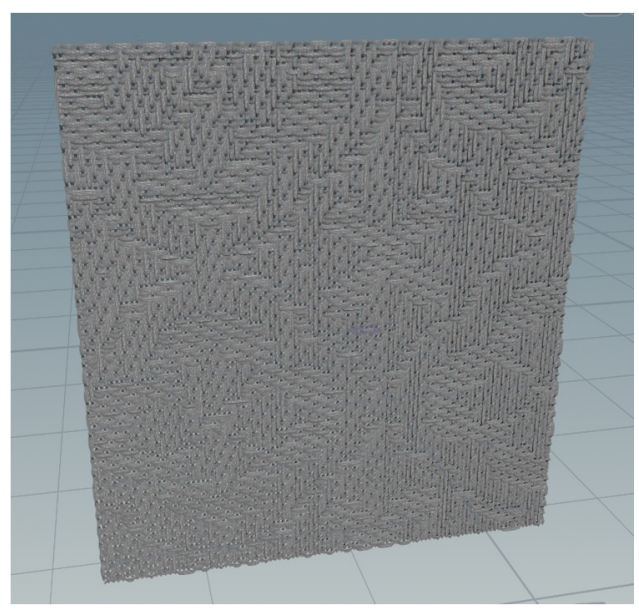

(a)

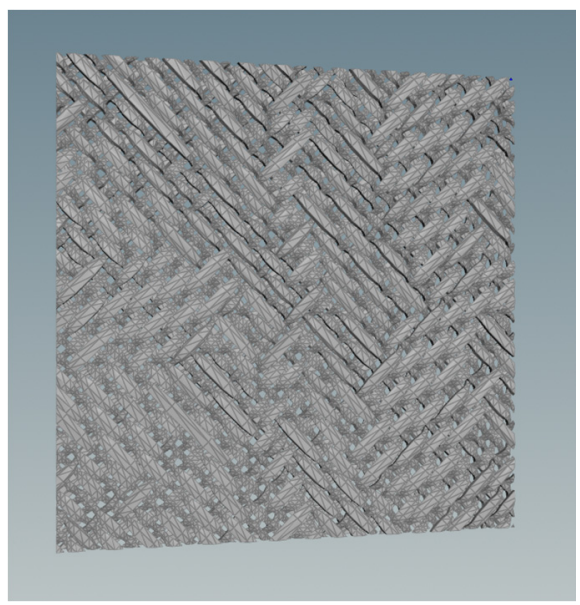

(b)

Figure 8. Models that represent weaving techniques: (a) original sample; (b) enlarged, rotated, and cropped for 3D printing. 


\subsubsection{Slicing and 3D Printing}

The slicing process is the process of creating G-code commands from the 3D model. With correct models, slicing produces predictable results. The toolpaths are clean, and the desired features are depicted with enough precision. The illustrative example in Figure 9 shows the generated G-codes out from correctly prepared models. Figure 9a depicts one printed layer viewed from the top, whereas Figure $9 \mathrm{~b}$ shows several layers in an orthogonal view. Each blue or purple line is a path the printhead will follow.

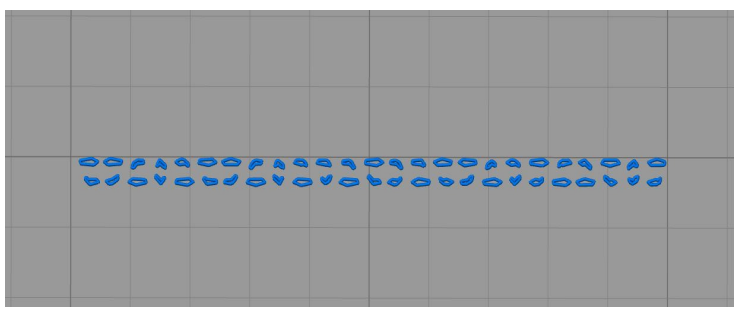

(a)

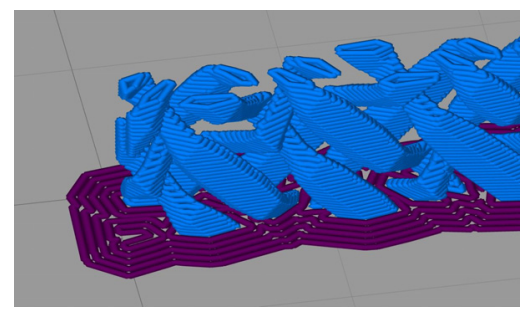

(b)

Figure 9. Example of correct G-codes: (a) top view of one layer; (b) orthogonal view of several layers.

The printing samples show that the G-codes were correct. The objects do not have typical errors, such as blobs of plastic sticking out, an uneven surface, holes in paths, etc. They have been printed correctly and have not fallen off the printing platform or deformed in an undesired way, nor have they overheated or failed in any other way. The preparations carried out provide failsafe, high quality print outs of Virtual Loom samples. Figure 10a shows an example of a design, and Figure 10b an example of a weaving technique.

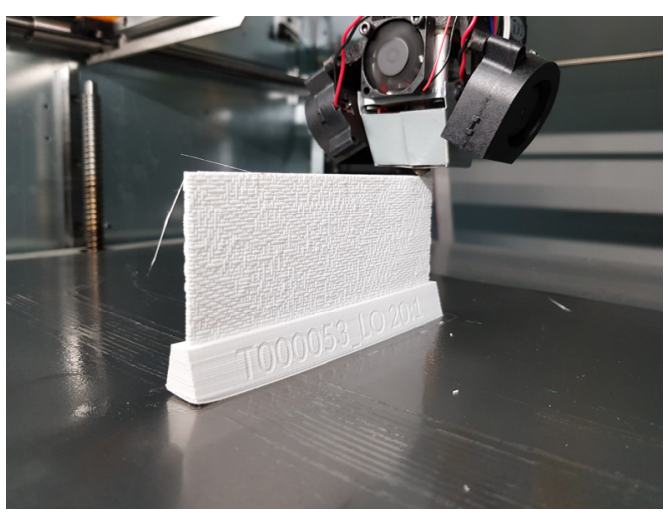

(a)

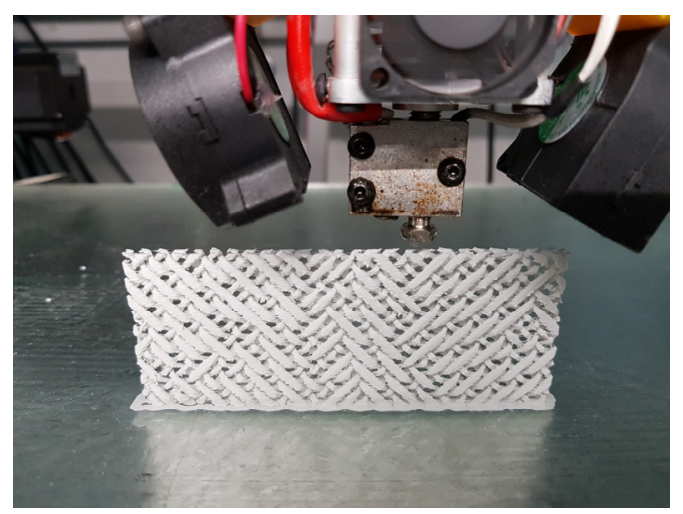

(b)

Figure 10. Printed samples: (a) a sample showing a design; (b) a sample showing a weaving technique.

\section{Discussion}

\subsection{Sustainability in 3D Modelling of Traditional Silk Fabrics: Conservation and Creative Industries}

The traditional silk industry can be already considered a sustainable industry as the machinery used is actioned manually without the use of energy; this is in fact important, as the global textiles and clothing industry are responsible for the consumption of 79 billion cubic meters of water, 1.715 million tons of $\mathrm{CO} 2$ emissions, and 92 million tons of waste [57]. On the other side, it is not mass produced, and hence it is a small and controlled production-fabrics are unique and unrepeatable, even if the same design is applied, modifications are infinite. 
Virtual Loom is directed to several audiences, being creative industries and museums, their primary target audiences. In this sense, Virtual Loom acts as a virtual memory that documents, preserves, and conserves historical weaving techniques, which represents one of the most important types of intangible heritage that are endangered. Indeed, every day there are fewer weavers that learn this ancient trade; moreover, as it is a traditional industry it usually is separated from academic canons. Virtual Loom connects traditional knowledge, intangible heritage, and academical research all together for the only purpose of conserving and disseminating silk heritage.

Creative industries can benefit from Virtual Loom in two ways. (1) For traditional industries, it represents a way of saving money as it allows for the visualization of fabrics and their modifications that can be applied to them, such as techniques, designs, colors, and materials with just one click. Without Virtual Loom, this implies weaving a small sample as many times as required by the client, which in the end turns up in spending time, money, and resources, which for many small companies it can be impossible to produce. (2) For fashion industries, it can be a way of appreciating their modern designs with a certain technique without using huge resources, especially in an industry as polluting as fashion, e.g., it allows for the modification of colors without applying dyes. Hence, Virtual Loom arises as a sustainable resource for creative industries related to textiles.

In museums, Virtual Loom and the derived 3D representations of fabrics can be applied in a twofold way. (1) For conservators, they can be useful to document and understand historical weaving techniques without handling historical fabrics that are extremely fragile and their conservation is very specific; in fact, international standards recommend not to handle these objects without need [10]. Virtual Loom has such a powerful visualization that it allows access to weaves and, therefore, the technique that was employed to produce a certain fabric. (2) As a didactic prop, they can be useful for educational departments that want to show non-expert audiences how a fabric is produced-audiences can see the obverse and reverse, they can move the 3D visualization, and they would be able also to "play" with different techniques, colors, materials, etc. and learn about silk heritage. In addition, the fact that these 3D models can be printed represent a sustainable path for museums as the same print can be used over and over, especially for children and people with special abilities.

The 3D representations of silk fabrics (in virtual forms and as printouts) maintain their cultural value acting as a medium to access this fragile heritage, as they democratize technical knowledge and aid in disseminating silk heritage. On the other hand, it has been proved that digital representation provides new opportunities to make abstract ideas visual and concrete [58]; at the same time, it allows new types of engagement. This is especially important when accessing certain types of heritage that, due to their own materiality, are difficult to understand or are extremely fragile. Virtual worlds allow having new experiences with heritage [59], adding value both to the experience and the cultural object itself.

Regarding the silk fabrics themselves, Virtual Loom adds a higher level of documentation in techniques, weaves, and yarns without damaging them, as the minimum information required is an image taken with a conventional camera, which is information already available at the museums' collections. Historical weaving techniques are not accessible to everyone. This knowledge is usually reserved to researchers and weavers. Virtual Loom was trained with this knowledge, and now it is open to everyone who wants to approach it. Users can look deep in the yarns and weaves, thanks to the navigation tools, and therefore to techniques. In this sense, it is worth mentioning that even non-existing objects can be studied today with Virtual Loom, provided that a picture exists, or even that a technical drawing exists. The derived virtual representations can be used in a variety of studies, such as art historical perspectives, as Virtual Loom allows for the completing of images or to reproduce those fabrics that only conserve technical drawings. It can also be used in fashion and design schools, because designers and students can select and practice with several types of yarns or weaves. Finally, from a conservation point of view, Virtual Loom favors non-invasive techniques in order to study weaving techniques. Indeed, thanks to the image analysis process integrated in Virtual Loom, that includes cropping an area of the original image, correction from perspective, changing of 
aspect ratio, axial symmetries, rotation, clustering, changing colors, etc.; many interesting uses can be derived. For instance, with the use of the axial symmetries, uncomplete images or damaged fabrics can be fully reproduced. Therefore, Virtual Loom can be useful to better document such objects. This has been demonstrated in [17], where we showed that, for the silk collection of Garin, 36\% of the records could benefit from this. Virtual representation of textiles can even be derived from ancient black and white images, also providing a more complete documentation. An example is shown in Figure 11, where a picture belonging to The Metropolitan Museum of Art (MET) has been loaded in Virtual Loom (in this case, with the standalone version). According to its description, it depicts a "carved and gilded walnut and poplar, upholstered with 18th-century blue and silver silk lampas". Therefore, we have applied the lampas technique, and used a silver yarn for the pictorial part. Additionally, the image has been automatically rectified, so the pictorial part is seen without perspective, differently from the original image.

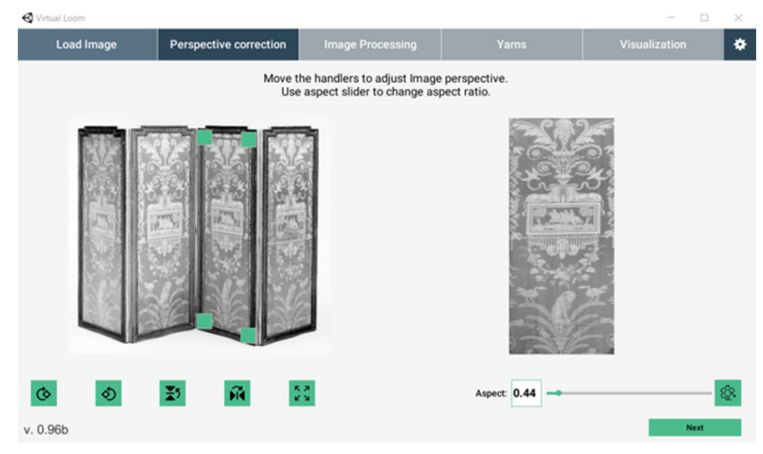

(a)

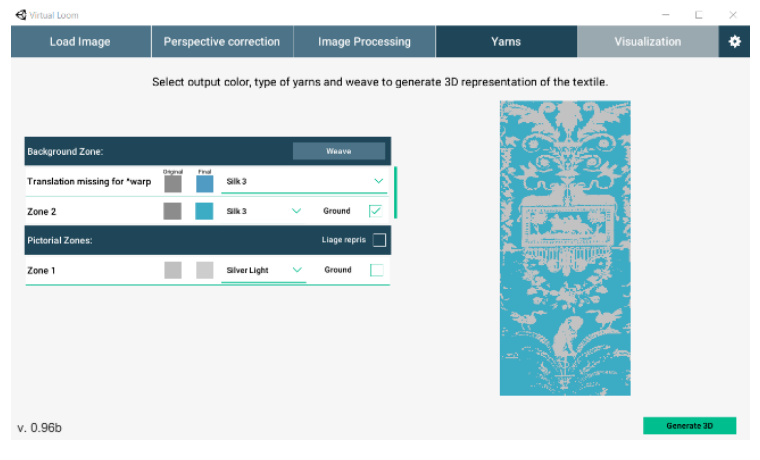

(c)

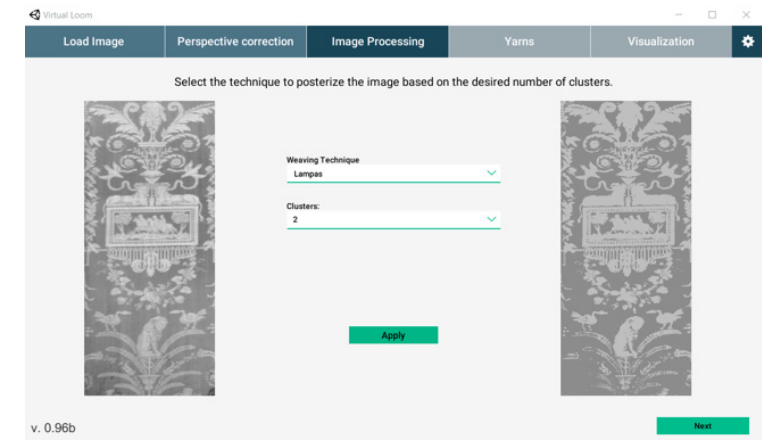

(b)

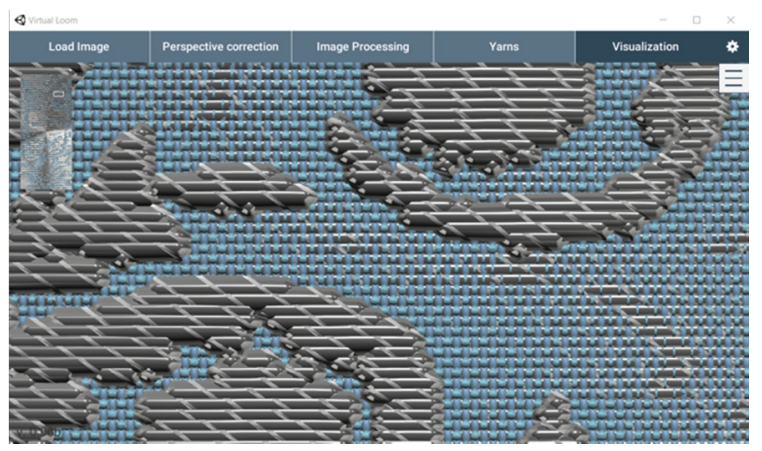

(d)

Figure 11. Example for the 3D reproduction of a historical fabric (from The Metropolitan Museum of Art (MET) [60]) in Virtual Loom v0.96b (standalone), with the lampas technique: (a) original image loaded in Virtual Loom, area selection, application of a vertical axial symmetry and aspect ratio fitting; (b) selection of the technique and number of clusters; (c) background, weave, yarn, and color selection; (d) interactive virtual representation.

\subsection{Sustainability in 3D Printing Production}

FFF 3D printing has become widely popular with lots of companies using 3D printing to enhance their workflow. Makers and enthusiasts all over the world use 3D printers at home.

The demand for common Polylactic Acid (PLA) filaments-a thermoplastic polymer that is derived from renewable resources, more specifically from corn starch or sugar cane-is growing steadily and has become a challenge for PLA source pellet producers. This means that more plastic is being produced. A large part of the plastic is used for the support structures and after being detached 
it goes straight to the garbage. A high percentage of 3D printed objects are temporary or test objects and have a short life span.

In terms of plastic garbage production, today 3D printing is not comparable to the production of packaging, toys, or other products, but the industry is growing and research on sustainability is needed.

\subsubsection{Using Bioplastics for 3D Printing}

Plastic waste can be found everywhere on earth, from the peak of Mount Everest down to the Challenger Deep. Disposed pieces disintegrate into tiny particles and will last for hundreds of thousands of years, poisoning every living organism. On the other hand, bioplastics are materials created out of renewable sources which can be consumed by protozoa, and thus decompose into simple, non-toxic chemical compounds. Therefore, research into bioplastics is a high priority.

PLA is one of them. While it is considered biodegradable, PLA waste has to be composted under special conditions in order to fully disintegrate. Successful composting of PLA is impossible today, as it goes into the same container as a lot of different polymers. At present, PLA is being burned along with many other plastic material wastes in order to recover energy. To effectively dispose of PLA, it has to be separated from other plastics, otherwise it is just another pollutant.

There are other polymers, such as Polyhydroxyalkanoate (PHA), which could develop promising properties that are worth waiting for. PHA is recovered from bacteria that store it as their energy source, and it biodegrades in the ambient environment. It could be used to produce food packaging, straws, and other products that inevitably end up in the environment [61].

Three-dimensional printing is not a high-volume technology. It is not used to manufacture disposable goods. The desirable properties of a 3D printed object are its durability, resistance to the environment (UV, temperature, water), long term dimensional stability, and other features not commonly connected to desirable features of bioplastics. Three-dimensional printing is used to produce sculptures and statues for outdoor exhibitions. It is important that the sculpture will not decompose over the next few years, otherwise it could be a real threat.

PHA is not widely used in the 3D printing industry yet; the availability of PHA filaments is inferior to the overwhelming availability of PLA and Polyethylene Terephthalate (PET). While PLA is known to withstand harsh conditions and remain stable through the years, the properties of PHA and PHA mixed filaments are neither well tested nor trusted by the 3D printing community. It could become the bioplastic of the future, when its popularity and availability grow. If not in industrial 3D printing, for sure at the consumer level, but most notably for the disposable goods (packaging, straws, disposable plastic cutlery, etc.) market.

As public awareness rises, the demand for bioplastics can only grow. Experimental polymers are eagerly used by makers and small design companies, but industry requires durable, tested materials, such as ABS (Acrylonitrile Butadiene Styrene) or polyamide, and this is not going to change soon. Industrial 3D printing produces machine parts which have to be durable, chemically resistant, and behave in a predictable way throughout the years. Bioplastics are not a contender in this area, and they will not replace technical materials. In fact, bioplastics are not the solution for today; their development has a long way to go before any serious usage in the 3D printing world will be seen.

\subsubsection{Making Filament from Recycled Plastic}

Recycling is a much easier and tenable solution. A polymer has to sustain its properties during the recycling process. Most common plastics do not, but PET polymer, out of which most plastic bottles are produced, is an exception. Its properties do not change during the recycling process. There is recycled PET filament on the market that contains $80 \%$ plastic from scrap bottles.

At the moment, the price of recycled PET is too high to consider it as competition for PLA in the mass market, but the direction is very promising. PET filaments are second in popularity. They are easy to print and produce high quality results. 
Apart from ready-made recycled filament, there are a few machines for home and studio use that produce filaments from plastic scraps. They are by no means comparable to industrial filament extruders, but the movement is gaining traction. With these machines, it is easy to produce filament out of almost any plastic. Recycling is the solution that can be readily used; it will only become more popular and available.

\subsubsection{D Printer Power Consumption}

The process of 3D printing is very time consuming and usually takes several hours. Almost all FFF 3D printers are equipped with heated nozzles, and a heated chamber or a heated bed. Power consumption of a common printer is around 120-200 W for a small sized one, and several $\mathrm{kW}$ for large industrial machines. Many consumer level printers are open, and the heat produced by the heated bed is dissipated. In cold countries, this is not necessarily a problem because the heat generated helps to heat up the house or office. It is desirable, and much more energy efficient, to use enclosed printers where the heat loss is much lower. Several printers working constantly for days consume a lot of power, and the carbon footprint of their work is not negligible. As energy prices go up, companies are starting to take this into account. There are many more enclosed printers today than a few years ago. They are more efficient, safer machines, which also provide better results due to stable thermal conditions during the printing process.

\section{Conclusions}

In this paper, we have described a new approach for the documentation, dissemination, and enhancement of historical silk fabrics at the yarn level, developed in the scope of the SILKNOW project. A section of methodology and results shows how to automatically extract information from text that is used to feed our tool, Virtual Loom. We also show how to extract the designs from images, and how a given design can be represented in 3D, making use of different traditional weaving techniques and the freestyle. Therefore, Virtual Loom adds a new level of fabric documentation, by means of a 3D shape. Finally, 3D printouts are also addressed, both for depicting designs and weaving techniques. With these experiments, we show how versatile Virtual Loom is in producing 3D representations of historical fabrics based on different weaves, yarns, and weaving techniques. Dissemination of silk fabrics is reinforced with ADASilk, our exploratory search engine built on top of the SILKNOW's knowledge graph that contains nearly 40,000 fabric entries. Overall, the enhancement of silk fabrics comes from the multiple uses that Virtual Loom and the 3D printouts have, which have been also discussed in the paper.

In the discussion section, we have shown how our solution is sustainable from different perspectives. For instance, Virtual Loom allows for the studying of the complexity of this fragile heritage without the need for accessing the real objects, thus avoiding their degradation; and the research on bioplastics for 3D printing is promising, as it contributes to environmental sustainability.

As further work, we intend to carry out massive, online evaluations of Virtual Loom, taking into consideration different targeted audiences, that include both SSH (Social Sciences and Humanities) and ICT (Information and Communication Technologies) experts, and the general public. As a result of such evaluation, we will provide an improved version of Virtual Loom, that will be openly available at [50,51] and accessible through ADASilk [53]. We will also evaluate the results of 3D printing material, that will be showcased in different events across Europe.

Author Contributions: Conceptualization, M.P., P.C.-S., J.G., M.F., P.T. (Pawel Twardo), P.T. (Piotr Twardo), A.L., D.M., B.M.M., R.T., T.E., E.R., G.L.C., M.V., C.P. and M.G.; methodology, M.P., P.C.-S., J.G., C.P., D.M., B.M.M., R.T., P.T. (Pawel Twardo), and P.T. (Piotr Twardo); software, M.P., P.C.-S., J.G., C.P., D.M., B.M.M., R.T., P.T. (Pawel Twardo) and P.T. (Piotr Twardo); validation, M.P., P.C.-S., J.G., P.T. (Pawel Twardo), P.T. (Piotr Twardo), D.M., B.M.M., R.T., T.E., A.L., C.P. and M.G.; formal analysis, M.P., P.C.-S., J.G., M.F., P.T. (Pawel Twardo), P.T. (Piotr Twardo), A.L., D.M., B.M.M., R.T., E.R., G.L.C., M.V., C.P. and M.G.; investigation, M.P., P.C.-S., J.G., M.F., P.T. (Pawel Twardo), P.T. (Piotr Twardo), A.L., D.M., B.M.M., R.T., E.R., G.L.C., M.V., C.P. and M.G.; resources, M.F., P.T. (Pawel Twardo), P.T. (Piotr Twardo), E.R. and C.P.; data curation, G.L.C., M.V., A.L. and E.R.; writing一original 
draft preparation, J.G., P.T. (Pawel Twardo), P.T. (Piotr Twardo), A.L., D.M., B.M.M., R.T., T.E., G.L.C., M.V., C.P. and M.G.; writing-review and editing, J.G., P.T. (Pawel Twardo), P.T. (Piotr Twardo), A.L., D.M., B.M.M., R.T., G.L.C., M.V., C.P. and M.G.; visualization, M.P., P.C.-S., J.G., P.T. (Pawel Twardo), P.T. (Piotr Twardo) and C.P.; supervision, M.F. and C.P.; project administration, M.F. and C.P.; funding acquisition, M.F., C.P., D.M., R.T. and M.G. All authors have read and agreed to the published version of the manuscript.

Funding: The research leading to these results is in the frame of the "SILKNOW. Silk heritage in the Knowledge Society: from punched cards to big data, deep learning and visual/tangible simulations" project, which has received funding from the European Union's Horizon 2020 research and innovation program under grant agreement No. 769504. Cristina Portalés is supported by the Spanish government postdoctoral grant Ramón y Cajal, under grant No. RYC2018-025009-I.

Conflicts of Interest: The authors declare no conflict of interest.

\section{References}

1. Portalés, C.; Casas, S.; Alonso-Monasterio, P.; Viñals, M.J. Multi-Dimensional Acquisition, Representation, and Interaction of Cultural Heritage Tangible Assets: An Insight on Tourism Applications. In Handbook of Research on Technological Developments for Cultural Heritage and eTourism Applications; IGI-Global: Hershey, PA, USA, 2018; Volume 95, pp. 72-95. [CrossRef]

2. Liarokapis, F.; Petridis, P.; Andrews, D.; de Freitas, S. Multimodal Serious Games Technologies for Cultural Heritage. In Mixed Reality and Gamification for Cultural Heritage; Ioannides, M., Magnenat-Thalmann, N., Papagiannakis, G., Eds.; Springer International Publishing: Cham, Switzerland, 2017; pp. 371-392. ISBN 978-3-319-49607-8.

3. Alivizatou-Barakou, M.; Kitsikidis, A.; Tsalakanidou, F.; Dimitropoulos, K.; Giannis, C.; Nikolopoulos, S.; Al Kork, S.; Denby, B.; Buchman, L.; Adda-Decker, M.; et al. Intangible Cultural Heritage and New Technologies: Challenges and Opportunities for Cultural Preservation and Development. In Mixed Reality and Gamification for Cultural Heritage; Ioannides, M., Magnenat-Thalmann, N., Papagiannakis, G., Eds.; Springer International Publishing: Cham, Switzerland, 2017; pp. 129-158. ISBN 978-3-319-49607-8.

4. Albert, M.-T.; Bernecker, R.; Rudolff, B. Understanding Heritage: Perspectives in Heritage Studies; Walter de Gruyter: Berlin, Germany, 2013; ISBN 978-3-11-030838-9.

5. Aicardi, I.; Chiabrando, F.; Maria Lingua, A.; Noardo, F. Recent trends in cultural heritage 3D survey: The photogrammetric computer vision approach. J. Cult. Herit. 2018, 32, 257-266. [CrossRef]

6. Grussenmeyer, P.; Alby, E.; Assali, P.; Poitevin, V.; Hullo, J.-F.; Smigiel, E. Accurate documentation in cultural heritage by merging TLS and high-resolution photogrammetric data. In Videometrics, Range Imaging, and Applications XI; International Society for Optics and Photonics: Washington, DC, USA, 2011; Volume 8085, p. 808508.

7. Navarro, S.; Seguí, A.E.; Portalés, C.; Lerma, J.L.; Akasheh, T.; Haddad, N. Integration of tls Data and Non-Metric Imagery to Improve Photo Models and Recording-A Case Study on Djin Block no. 9, Petra (Jordan); IEEE: Piscataway, NJ, USA, 2009; pp. 58-63.

8. Roman, C.; Inglis, G.; Rutter, J. Application of structured light imaging for high resolution mapping of underwater archaeological sites. In Proceedings of the OCEANS'10 IEEE SYDNEY, Sydney, Australia, 24-27 May 2010; pp. 1-9.

9. León Muñoz, A.; Roca Cabrera, M. The Moncada Silk Museum, the case of the Garín factory. Datatèxtil 2016, 34, 2-10.

10. Expinoza, F.; Grüzmacher, M.L. Manual de Conservación Preventiva de Textiles; Comité Nacional de Conservación Textil, Dirección de Bibliotecas, Archivos y Museos, Fundación Andes: Medellín, Colombia, 2002.

11. Éri, I. Conserving Textiles: Studies in Honour of Ágnes Timár-Balázsy|ICCROM; Conservation Studies Number 7; ICCROM: Rome, Italy, 2009; ISBN 92-9077-218-2.

12. Wijaya, W.; Ali, M.A.; Umer, R.; Khan, K.A.; Kelly, P.A.; Bickerton, S. An automatic methodology to CT-scans of 2D woven textile fabrics to structured finite element and voxel meshes. Compos. Part A Appl. Sci. Manuf. 2019, 125, 105561. [CrossRef]

13. Ahmed, H.E.; Darwish, S.S. Effect of Museum Conditions on Historical Dyed Silk Fabric with Madder Dye. J. Polym. Environ. 2012, 20, 596-606. [CrossRef]

14. Koussoulou, T. Photodegradation and photostabilization of historic silks in the museum environment-evaluation of a new conservation treatment. Pap. Inst. Archaeol. 1999, 10, 75-88. [CrossRef] 
15. Portalés, C.; Sebastián, J.; Alba, E.; Sevilla, J.; Gaitán, M.; Ruiz, P.; Fernández, M. Interactive Tools for the Preservation, Dissemination and Study of Silk Heritage-An Introduction to the SILKNOW Project. Multimodal Technol. Interact. 2018, 2, 28. [CrossRef]

16. Portalés, C.; Sevilla, J.; Pérez, M.; León, A. A Proposal to Model Ancient Silk Weaving Techniques and Extracting Information from Digital Imagery-Ongoing Results of the SILKNOW Project; Faro: Algarve, Portugal, 2019.

17. Gaitán, M.; Portalés, C.; Sevilla, J.; Alba, E. Applying Axial Symmetries to Historical Silk Fabrics: SILKNOW's Virtual Loom. Symmetry 2020, 12, 742. [CrossRef]

18. Gaitán, M.; Alba, E.; León, A.; Pérez, M.; Sevilla, J.; Portalés, C. Towards the Preservation and Dissemination of Historical Silk Weaving Techniques in the Digital Era. Heritage 2019, 2, 1892-1911. [CrossRef]

19. Gang, Z.; Bingbing, D.; Wenjuan, Z.; Yali, Y.; Hui, Z. Design and implementation of interactive system for Tujia brocade virtual weaving based on kinect. In Proceedings of the 2017 23rd International Conference on Automation and Computing (ICAC), Huddersfield, UK, 7-8 September 2017; pp. 1-5.

20. MAGIC FABRIC-A Blog about 3D Fashion. Available online: https://magicfabricblog.com/ (accessed on 3 September 2020).

21. Boyce, A.; Doran, K.; Campbell, A.; Pickford, S.; Culler, D.; Barnes, T. BeadLoom Game: Adding competitive, user generated, and social features to increase motivation. In Proceedings of the 6th International Conference on Foundations of Digital Games, Bordeaux, France, 29 June-1 July 2011; Association for Computing Machinery: New York, NY, USA, 2011; pp. 139-146.

22. Clair, K.S. La Trama del Mondo. I Tessuti che Hanno Fatto la Storia; UTET: Torino, Italy, 2019; ISBN 978-88-511-7430-9.

23. Orsini, B. Alle origini del tessuto. In Il filo Della Storia; Constantini, M., Silvestri, I., Eds.; CLUEB: Bologna, Italy, 2005.

24. Ota, Y. L'industria tessile. In Instituto Della Enciclopedia Italiana, Enciclopedia Italiana di Scienze Lettere ed Arti: Il Contributo Italiano alla Storia del Pensiero; RICCI: Roma, Italy, 2013; pp. 615-629.

25. Donnanno, A. Modabolario. Parole e Immagini Della Moda. Dizionario Tecnico-Creativo, 2nd ed.; Ikon: Milano, Italy, 2018; ISBN 978-88-89628-36-2.

26. Azzali, M. Dizionario di Costume e Moda. Dal filo all'abito, 2nd ed.; Mancosu Editore: Roma, Italy, 2015; ISBN 978-88-96589-21-2.

27. Boccherini, T.; Marabelli, P. Atlante di Storia del Tessuto. Itinerario nell'arte Tessile Dall'antichità al Déco. Ediz. Italiana e Inglese; MCM-Maria Cristina de Montemayor: Florence, Italy, 1995; ISBN 978-88-906708-2-4.

28. Gentile, A. Dizionario Etimologico dell'arte Tessile; Società Editrice Napoletana: Naples, Italy, 1981.

29. Regensteiner, E. The Art of Weaving; Schiffer Pub.: Atglen, PA, USA, 1986; ISBN 978-0-88740-079-7.

30. Devoti, D. L'arte del Tessuto in Europa; Bramante: Rome, Italy, 1993; ISBN 978-88-7939-005-7.

31. Cuoghi Costantini, M. I tessuti del '700: La seduzione della tecnologia. In La Collezione Gandini del Museo Civico di Modena. I tessuti del XVIII e XIX secolo; Devoti, D., Guandalini, G., Bazzani, E., Cuoghi Costantini, M., Eds.; TESSUTI: Bologna, Italy, 1985; p. 457.

32. Espolines de Garín. 1820. Available online: http://garin1820.com/ (accessed on 3 September 2020).

33. Wu, K.; Yuksel, C. Real-time Fiber-level Cloth Rendering. In Proceedings of the 21st ACM SIGGRAPH Symposium on Interactive 3D Graphics and Games, San Francisco, CA, USA, 25-27 February 2017; ACM: New York, NY, USA, 2017; pp. 5:1-5:8.

34. Kaldor, J.M.; James, D.L.; Marschner, S. Simulating Knitted Cloth at the Yarn Level. In Proceedings of the ACM SIGGRAPH 2008 Papers; ACM: New York, NY, USA, 2008; pp. 65:1-65:9.

35. Cirio, G.; Lopez-Moreno, J.; Otaduy, M.A. Efficient Simulation of Knitted Cloth Using Persistent Contacts. In Proceedings of the 14th ACM SIGGRAPH / Eurographics Symposium on Computer Animation; ACM: New York, NY, USA, 2015; pp. 55-61.

36. Lomov, S.V.; Huysmans, G.; Verpoest, I. Hierarchy of Textile Structures and Architecture of Fabric Geometric Models. Text. Res. J. 2001, 71, 534-543. [CrossRef]

37. Lomov, S.V. Modelling the Geometry of Textile Composite Reinforcements; WiseTex: Nairobi, Kenya, 2011.

38. Lomov, S.V. WiseTex Software Suite; CMG: Beijing, China, 2005.

39. TexGen. Available online: http://texgen.sourceforge.net/index.php/Main_Page (accessed on 23 November 2018).

40. Neumüller, M.; Reichinger, A.; Rist, F.; Kern, C. 3D Printing for Cultural Heritage: Preservation, Accessibility, Research and Education. In 3D Research Challenges in Cultural Heritage: A Roadmap in 
Digital Heritage Preservation; Ioannides, M., Quak, E., Eds.; Lecture Notes in Computer Science; Springer: Berlin/Heidelberg, Germany, 2014; pp. 119-134. ISBN 978-3-662-44630-0.

41. Jung, T.H.; tom Dieck, M.C. Augmented reality, virtual reality and 3D printing for the co-creation of value for the visitor experience at cultural heritage places. J. Place Manag. Dev. 2017, 10, 140-151. [CrossRef]

42. Scopigno, R.; Cignoni, P.; Pietroni, N.; Callieri, M.; Dellepiane, M. Digital Fabrication Techniques for Cultural Heritage: A Survey. Comput. Graph. Forum 2017, 36, 6-21. [CrossRef]

43. Sabantina, L.; Kinzel, F.; Ehrmann, A.; Finsterbusch, K. Combining 3D printed forms with textile structures -Mechanical and geometrical properties of multi-material systems. IOP Conf. Ser. Mater. Sci. Eng. 2015, 87, 012005. [CrossRef]

44. Melnikova, R.; Ehrmann, A.; Finsterbusch, K. 3D printing of textile-based structures by Fused Deposition Modelling (FDM) with different polymer materials. IOP Conf. Ser. Mater. Sci. Eng. 2014, 62, 012018. [CrossRef]

45. Pei, E.; Shen, J.; Watling, J. Direct 3D printing of polymers onto textiles: Experimental studies and applications. Rapid Prototyp. J. 2015, 21, 556-571. [CrossRef]

46. Rivera, M.L.; Moukperian, M.; Ashbrook, D.; Mankoff, J.; Hudson, S.E. Stretching the Bounds of 3D Printing with Embedded Textiles; ACM: New York, NY, USA, 2017; pp. 497-508.

47. Janne Kyttanen. Available online: https://www.jannekyttanen.com (accessed on 3 September 2020).

48. Iris van Herpen. Available online: http://www.irisvanherpen.com:443/ (accessed on 3 September 2020).

49. Noa Raviv. Available online: https://www.noaraviv.com/ (accessed on 3 September 2020).

50. Silknow/Virtual-Loom. Available online: https://github.com/silknow/virtual-loom (accessed on 10 August 2020).

51. Virtual Loom, Release History. Available online: https://silknow.eu/virtualLoom/ (accessed on 10 August 2020).

52. Virtual Loom Tutorial. Available online: https://www.youtube.com/watch?time_continue=5\&v=oaZqM3Wli8\&feature=emb_logo (accessed on 10 August 2020).

53. ADASilk. Available online: https://ada.silknow.org/en (accessed on 10 August 2020).

54. Lisena, P.; Meroño-Peñuela, A.; Kuhn, T.; Troncy, R. Easy Web API Development with SPARQL Transformer; Springer: Auckland, New Zealand, 2019.

55. Palagi, E.; Gandon, F.; Troncy, R.; Giboin, A. A Survey of Definitions and Models of Exploratory Search; Springer International Publishing: Cham, Switzerland, 2017; p. 3.

56. Mladenić, D.; Gaitán, M.; Troncy, R. SILKNOW-Multilingual Text Analysis for Silk Heritage. In Proceedings of the 25th ACM SIGKDD International Conference on Knowledge Discovery \& Data Mining (KDD '19), Anchorage, AK, USA, 4-8 August 2019; Association for Computing Machinery: New York, NY, USA, 2019; pp. 1-2.

57. Šajn, N. Environmental Impact of the Textile and Clothing Industry: What Consumers Need to Know; European Parliament: Strasbourg, France, 2019.

58. King, L.; Stark, J.F.; Cooke, P. Experiencing the Digital World: The Cultural Value of Digital Engagement with Heritage. Herit. Soc. 2016, 9, 76-101. [CrossRef]

59. Hogsden, C.; Poulter, E.K. The real other? Museum objects in digital contact networks. J. Mater. Cult. 2012. [CrossRef]

60. Four-Leaf Folding Screen (Paravent) | French | The Met. Available online: https://www.metmuseum.org/art/ collection/search/205091 (accessed on 16 August 2020).

61. van der Hoeven, D. PHA: Promising, Versatile, Biodegradable. Available online: https://www.biobasedpress. eu/2016/08/pha-promising-versatile-biodegradable/ (accessed on 9 August 2020).

(C) 2020 by the authors. Licensee MDPI, Basel, Switzerland. This article is an open access article distributed under the terms and conditions of the Creative Commons Attribution (CC BY) license (http://creativecommons.org/licenses/by/4.0/). 